\title{
Assistive technologies for pain management in people with amputation: a literature review
}

\author{
Kamiar Ghoseiri ${ }^{1}$, Mostafa Allami ${ }^{2 *}$, Mohammad Reza Soroush² and Mohammad Yusuf Rastkhadiv ${ }^{3}$
}

\begin{abstract}
The prevalence of limb amputation is increasing globally as a devastating experience that can physically and psychologically affect the lifestyle of a person. The residual limb pain and phantom limb pain are common disabling sequelae after amputation surgery. Assistive devices/technologies can be used to relieve pain in people with amputation. The existing assistive devices/technologies for pain management in people with amputation include electrical nerve block devices/technologies, TENS units, elastomeric pumps and catheters, residual limb covers, laser systems, myoelectric prostheses and virtual reality systems, etc. There is a great potential to design, fabricate, and manufacture some portable, wireless, smart, and thin devices/technologies to stimulate the spinal cord or peripheral nerves by electrical, thermal, mechanical, and pharmaceutical stimulus. Although some preliminary efforts have been done, more attention must be paid by researchers, clinicians, designers, engineers, and manufacturers to the post amputation pain and its treatment methods.
\end{abstract}

Keywords: Amputees, Amputation stumps, Self-help devices, Pain, Acute pain, Chronic pain, Pain management

\section{Background}

Limb amputation is a devastating experience that can physically and psychologically affect the lifestyle of a person [1]. Although there is no estimate of the global prevalence of limb amputation, national reports of some countries confirmed the increase in population of people with amputation [2, 3]. In most patients, amputation can cause two different kinds of pain, the phantom limb pain and the residual limb pain. Debilitating pain is associated with the burden of extra costs of treatment and the lost productivity of patients $[4,5]$. Pain can affect the quality of life, outlook, personality, and relations of people with amputation. In addition, it can impede their rehabilitation and prosthesis use [6-9]. Kooijman et al. [10] in an epidemiological study, determined that the prevalence of phantom limb pain and residual limb pain is 51\% and $47 \%$, respectively.

\footnotetext{
* Correspondence: Iranassistive@gmail.com

2Janbazan Medical and Engineering Research Center (JMERC), Farrokh Ave, Velenjak, Tehran, Iran

Full list of author information is available at the end of the article
}

\section{Category of pain}

\section{Phantom limb pain}

The majority of patients after a partial or complete amputation of a limb may feel that the amputated part of the body is still present and suffer from pain [4, 11-13]. In spite of the ample literature on phantom limb pain, there is no consensus on the exact mechanism of such a feeling. In the literature, phantom limb pain has been attributed to genetic background, memories, neuromas (the painful end branches of a cut nerve), peripheral/ spinal dysfunction, supraspinal and central plasticity, and cortical re-mapping [14, 15]. Moreover, some physical, psychological, and weather-induced factors can increase the risk of phantom limb pain. Therefore, the existence of pre-amputation pain, the referral pain from the contralateral intact limb, neck or back, the emotional triggers such as stress, depression or thinking about the amputation, and temperature fluctuations all can trigger phantom limb pain [15]. Phantom limb pain in 50\% of cases is an intermittent and episodic pain, which may range from hours, days, weeks, years, to decades [16]. Sherman et al. [16] found that $78 \%$ of their participant amputees had complaints of phantom limb pain.

\section{Biomed Central}

(c) The Author(s). 2018 Open Access This article is distributed under the terms of the Creative Commons Attribution 4.0 International License (http://creativecommons.org/licenses/by/4.0/), which permits unrestricted use, distribution, and reproduction in any medium, provided you give appropriate credit to the original author(s) and the source, provide a link to the Creative Commons license, and indicate if changes were made. The Creative Commons Public Domain Dedication waiver (http://creativecommons.org/publicdomain/zero/1.0/) applies to the data made available in this article, unless otherwise stated. 
Moreover, the prevalence of phantom limb pain is higher in women and in those with upper extremity amputation [17].

\section{Residual limb pain}

Residual limb pain can be described as the pain derived from physical damage to body tissues, especially at its distal end, during amputation surgery [13]. A main source of the residual limb pain is skin dermatosis, which is so prevalent in amputees with a range of $34 \%$ to $74 \%[18,19]$. Some common skin dermatoses include mechanically-induced problems, allergic reactions, and fungal infections [20]. Similar to phantom limb pain, the prevalence of residual limb pain is high. Yang et al. [21] reported the existence of residual limb pain in $61.5 \%$ of their 247 participant amputees.

\section{Pain management after amputation surgery}

Pain management after amputation surgery can be classified into three categories, which include medical, non-medical, and surgical treatments. Surgical treatment is an invasive method that is usually considered as the last choice. Cordotomy, root lesion, targeted nerve implantation, and targeted muscle reinnervation are common surgical procedures to prevent or decrease residual limb pain and phantom limb pain [22-25]. The longevity of pain relief after surgical treatment is not high and usually the neuroma will grow again after surgery $[15,26,27]$. In spite of some drawbacks, the medication therapy has a great popularity. Anti-depression, muscle relaxation, analgesic, and opioid drugs are common examples of medications that are prescribed in spite of their sideeffects $[28,29]$. Contrary to great drawbacks of medication therapy and surgery, non-medical treatments have shown some promising results.

The most common non-medical treatment is using soft or rigid dressing over the residual limb to control pain and edema, and prevent joint contracture [30]. Some other non-medical treatments include nerve block, Botox injection, exercise therapy, massage, heat/cold pack, vibration and electroshock therapy, transcutaneous electrical nerve stimulation (TENS), acupuncture, psychological and behavioral treatments such as hypnosis and biofeedback (e.g. virtual reality methods such as mirror box therapy) $[4,28]$. Although there are many disagreements about the beneficiary of non-medical treatments, they are more acceptable due to their fewer drawbacks. However, it is worth mentioning that some non-medical treatments such as nerve block may need some minor surgeries to place an assistive device/technology under the skin.

The assistive technology industrial association has defined assistive technology as any item, piece of equipment, software or product that can be used for increasing, maintaining, or improving the functional capabilities of individuals with disabilities [31]. The present review aimed to explore the literature to find existing assistive devices/ technologies for pain management in people with amputation. Furthermore, the results of present review can provide an insight on current advances and limitations in pain management after amputation [32], which consequently, can promote peers to focus further on resolving the problem in future.

\section{Available assistive devices/technologies} Electrical nerve block devices/technologies

Electrical nerve block can be used as an assistive device to alleviate pain in people with amputation [33]. In this regard, the Neuros Medical Inc. (Cleveland, OH, USA) has introduced a commercially available assistive device/ technology to alleviate pain based on electrical nerve block. It is an electrical nerve blocker that applies high frequency sinusoidal waveforms of $10 \mathrm{kHz}$ and up to $10 \mathrm{~V}$ proximal to the neuroma at a peripheral nerve (Fig. 1). This device consists of electrode, external or internal waveform generator, power supply, data logger, and an external remote controller to start pain relief when it is needed. The main problem of this assistive device is the need for surgery to implant the electrode around the nerve and its generator in a subcutaneous

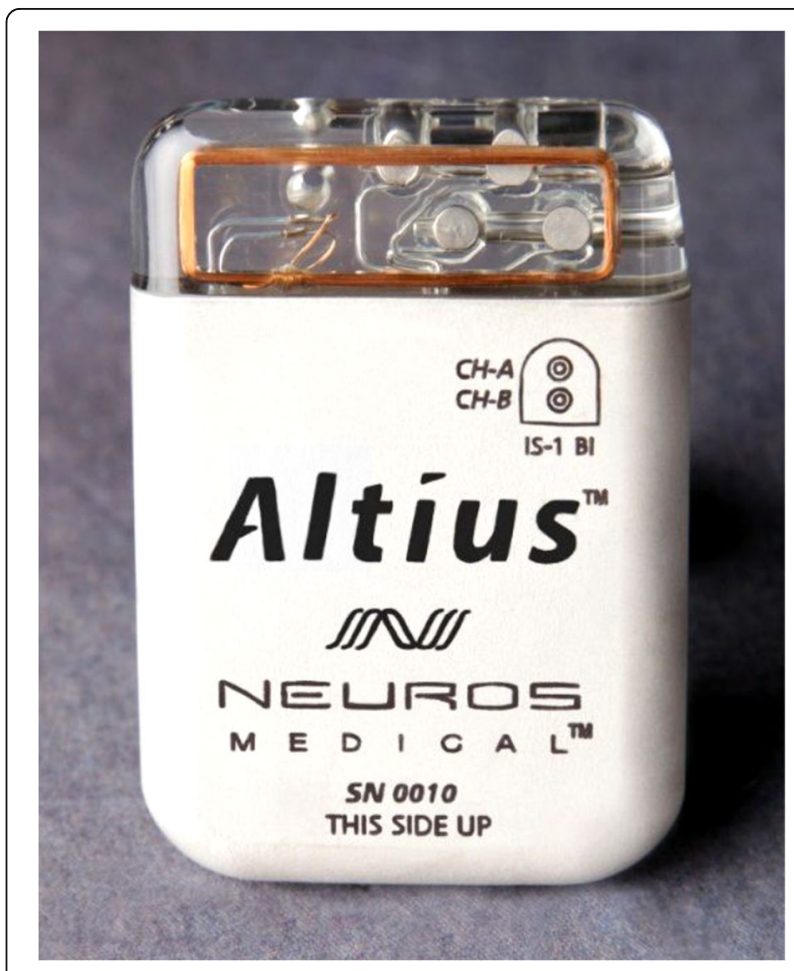

Fig. 1 Electrical nerve block device/technology [https://www.neurosmedical.com/about/the-altius-system/] 
pocket in the abdominal region just below the rib cage. In spite of promising primary results of using this device to relieve pain in some amputees, more research is warranted to confirm its long time effects in a large group of amputees [33].

Rauck et al. [34] introduced another assistive device/ technology for pain relief after amputation. The prototype of their device consisted of a fine-wire lead, an electrical stimulator, and a DC power supply. This prototype transferred electrical stimulations with a frequency of $50-100 \mathrm{~Hz}$ at a specific distance to the major peripheral nerves, i.e. femoral nerve or sciatic nerve, to produce paresthesia distal to the stimulation site. Their future plan was to develop the prototype as a smart patch nerve stimulator with skin-mounted stimulator and percutaneous lead after its safety and effectiveness evaluations.

\section{TENS units}

A TENS unit can be used as an assistive device/technology for pain relief after amputation (Fig. 2). Giuffrida et al. [35] used TENS on the contralateral (i.e. the healthy) limb of 2 participant amputees to evaluate its effect on pain relief. These authors confirmed the effectiveness of TENS in phantom limb pain relief. The effectiveness of TENS can be attributed to inhibiting the second order nociceptive neurons (analgesic effect), increasing blood flows, and reducing muscle spasms [36].

\section{Elastomeric pumps and catheters}

Elastomeric pump and catheter is an assistive device/technology that can infuse local anesthesia for pain relief in people with amputation. The SynchroMed II infusion pump (Medtronics Inc., USA) is a commercially available assistive device/technology that produces analgesic effects

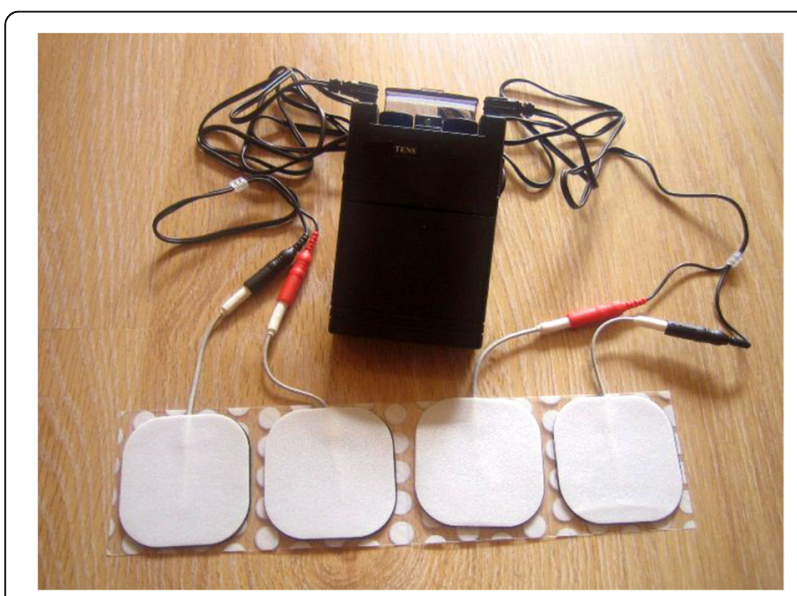

Fig. 2 The transcutaneous electrical nerve stimulation unit [https:// en.wikipedia.org/wiki/Transcutaneous_electrical_nerve_stimulation]

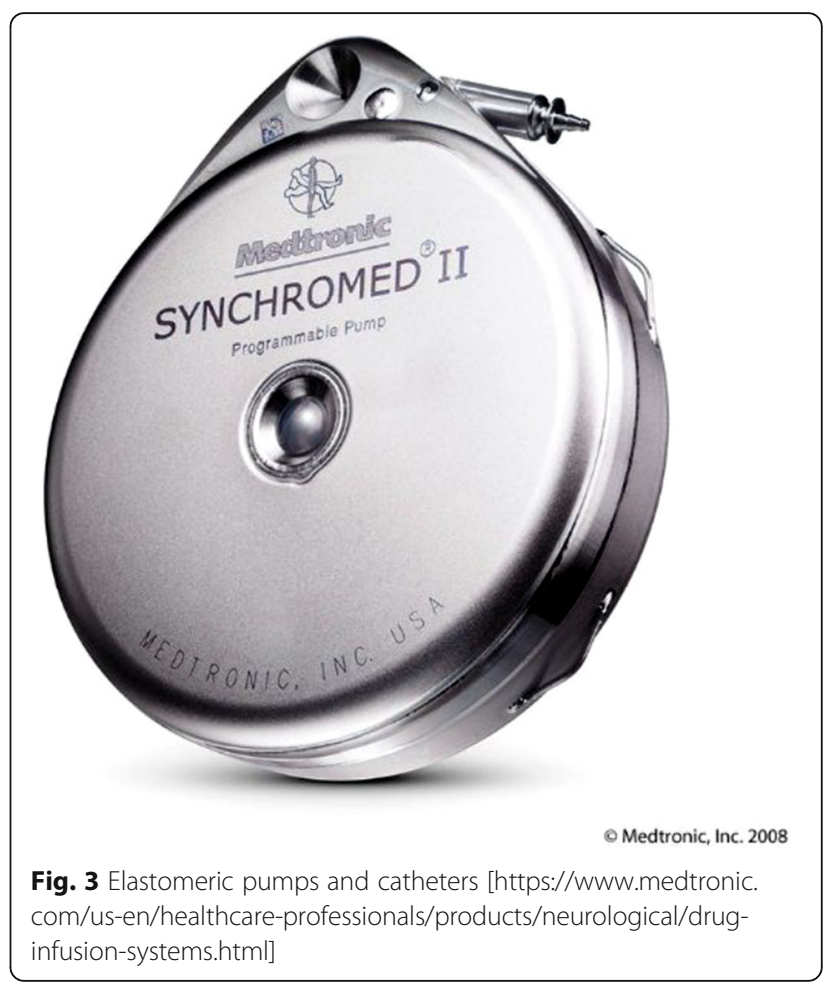

by infusion of anesthesia (Fig. 3) [37]. This assistive device/technology is totally or partially implantable and can inject drugs to the subarachnoid or epidural space by activating a programmable or manual pump [38]. Therefore, the need for surgery, high cost, and high risk of infection are main problems associated with this assistive device/ technology [38]. However, the results of a systematic review with meta-analysis showed that application of perineural local anaesthetic catheters alongside the transected sciatic nerve (for transfemoral amputations) or tibial nerve (for transtibial amputations) were possibly effective in pain relief [39]. Although they can approximately halve the postoperative opioid consumption, further investigation is warranted to determine their immediate pain relief after amputation [39].

\section{Residual limb covers}

Some specially designed and manufactured residual limb covers such as Farabloc and Medipro Liner Relax are applicable as assistive device/technology for pain relief in people with amputation (Fig. 4). The Farabloc was introduced by a Canadian company in 1993, as a special garment that comprised of a series of ultrathin steel threads woven into linen fabrics [40]. The Farabloc has the capability to prevent exposure of nerve endings of the residual limb to external electric and magnetic fields [40]. There are some controversial reports regarding the effectiveness of Farabloc. In a randomized controlled study, it was 


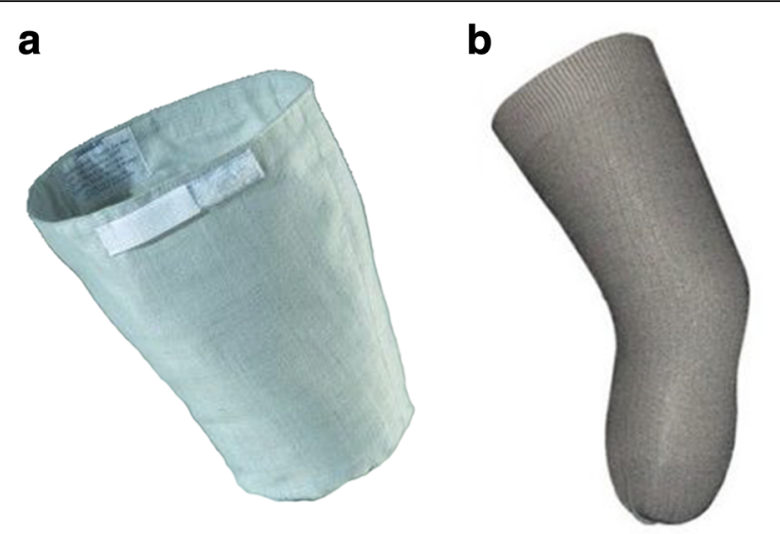

Fig. 4 The Farabloc (a) and Medipro Relax (b) liners

shown that Farabloc had no significant effect in reducing phantom limb pain after 12 weeks of use [41]. Zhang et al. [42] confirmed that the Farabloc was effective in alleviating delayed muscle soreness and pain in non-amputee people. Although satisfactory pain relief was reported by some amputees in the short-term use of Farabloc, further investigation is warranted to determine its effectiveness in the long-term, e.g. a year after amputation, use [40]. The Medipro Relax Liner was introduced in 2006 by a German-based company as an electromagnetically shielding liner with woven metals to cover the residual limb. This idea was derived from anecdotal experience of some people with amputation who wrapped their residual limb with aluminum foil to decrease phantom limb pain [43]. This liner has an electrical direct current with a resistance of 20 to 200 Ohms that flows from proximal to distal through an electromagnetic shield cover. Although it has been claimed that this electromagnetic shield significantly reduces the intensity of phantom limb pain, the mechanism of its action is unclear. Some possible mechanisms that have been suggested includes reduction of ectopic neuroma activity, shielding from electromagnetic impulses of weather, and analgesic effects due to changes in the electromagnetic field [43]. However, further research is required to confirm the effectiveness of this textile based liner and its underlying mechanism of action.

\section{Laser systems}

Auricular acupuncture with laser might be another treatment method to alleviate post amputation pain [44]. Jacobs et al. [44] reported satisfactory pain relief using laser system in an amputee with phantom limb pain. However, the design of their study was not strong enough to confirm the effectiveness of this treatment method.

\section{Myoelectric prostheses}

Myoelectric prostheses when equipped with some biofeedbacks are potentially assistive devices/technologies that can alleviate phantom limb pain [45]. However, further research is required to confirm their effectiveness.

\section{Virtual reality systems}

The virtual reality is the last assistive device/technology that was found in this literature review [46]. It can be used separately or in conjunction with a biofeedback system to relieve pain in people with amputation. The motion capture technology and the brain computer interface are common biofeedback systems that can be connected to virtual reality [46-48]. The simplest type of a virtual reality device/technology is a rectangular box, i.e. the mirror box, without roof and front surfaces that has been divided in its middle by a vertical mirror (Fig. 5). The amputee sits in front of the box, places the intact limb on one side of the box and looks into the mirror. Therefore, it seems that the amputated limb revived and can be moved simultaneously with movements of the intact limb $[49,50]$. This visual feedback causes the illusion in amputee and provides a bodily integrity sense that consequently can lead to cortical somatosensory reorganization. This process has been proved by MRI studies and reported as a satisfactory treatment for phantom limb pain [51]. However, further studies are required to confirm the effectiveness of virtual reality systems in alleviating phantom limb pain [52].

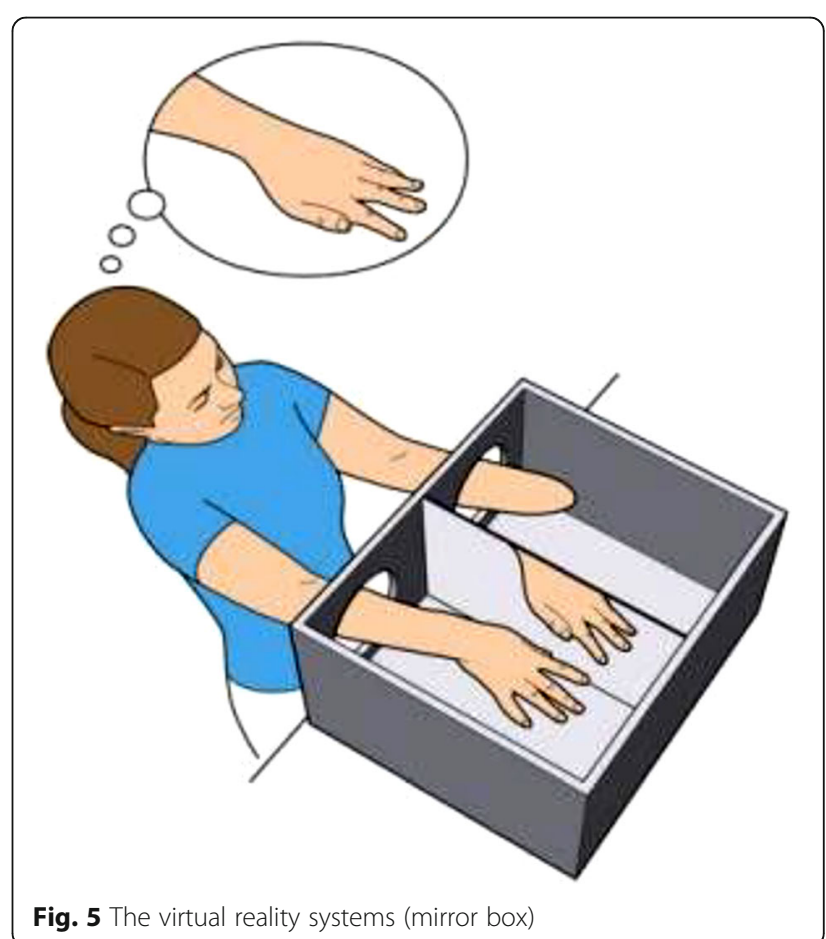




\section{Conclusions}

The present review clearly showed that the majority of the available assistive devices/technologies could relieve pain conservatively. However, some of them are working by infusing a medication and some needs surgery to place some components inside body. Therefore, there is no distinct border among the 3 classified pain treatment methods, i.e. medical, non-medical, and surgical treatments, when assistive devices/technologies are applied in people with amputation. However, due to great drawbacks of medical and surgical treatments, future designs of assistive devices/technologies can focus more on non-medical treatments. There is a great potential to design, fabricate, and manufacture some portable, wireless, smart, and thin assistive devices/technologies to stimulate the spinal cord or peripheral nerves by electrical, thermal, mechanical, and pharmaceutical stimulus. Although some preliminary efforts have been done in this regard, there are few numbers of commercially available assistive devices/technologies for pain management in people with amputation [53-58].

The overall pain relief can't easily be compared among assistive devices/technologies in this review due to different study designs, interventions, and characteristics of participants. Long-term randomized clinical trials are required to evaluate the effectiveness of available assistive devices/technologies. Considering the increasing population of people with amputation, high demand to assistive devices/technologies for pain management can be expected. Finally, more attention must be paid by researchers, clinicians, designers, engineers, and manufacturers to the post amputation pain and its treatment methods.

\section{Abbreviations}

JMERC: Janbazan Medical and Engineering Research Center;

TENS: Transcutaneous electrical nerve stimulation

\section{Acknowledgements}

The authors would like to sincerely thank the financial support of the Janbazan Medical and Engineering Research Center (JMERC), Tehran, Iran for this material.

\section{Funding}

This material was based on work supported by the Janbazan Medical and Engineering Research Center (JMERC).

\section{Availability of data and materials}

The datasets used and/or analyzed during the current study are available from the corresponding author on reasonable request.

\section{Authors' contributions}

$K G, M A$, and MS contributed in study concept and design. KG, MA, and MYR participated in data gathering. KG and MA analyzed and interpreted data. All authors contributed to drafting of the manuscript and read and approved the final manuscript.

Ethics approval and consent to participate Not applicable.

\section{Consent for publication}

Not applicable.

\section{Competing interests}

The authors declare that they have no competing interests.

\section{Author details}

${ }^{1}$ Department of Orthotics and Prosthetics, School of Rehabilitation Sciences, Hamadan University of Medical Sciences, Hamadan, Iran. ${ }^{2}$ Janbazan Medical and Engineering Research Center (JMERC), Farrokh Ave, Velenjak, Tehran, Iran. ${ }^{3}$ Department of Occupational Therapy, School of Rehabilitation

Sciences, Hamadan University of Medical Sciences, Hamadan, Iran.

Received: 28 June 2017 Accepted: 8 January 2018

Published online: 23 January 2018

\section{References}

1. Arias Vázquez PI, Castillo Avila RG, Dominguez Zentella MDC, HernándezDíaz Y, González-Castro TB, Tovilla-Zárate CA, et al. Prevalence and correlations between suicide attempt, depression, substance use, and functionality among patients with limb amputations. Int J Rehabil Res. 2017. https://doi.org/10.1097/MRR.0000000000000259. [Epub ahead of print]

2. Sabzi Sarvestani A, Taheri Azam A. Amputation: a ten-year survey. Trauma Mon. 2013;18(3):126-9

3. Ziegler-Graham K, MacKenzie EJ, Ephraim PL, Travison TG, Brookmeyer R. Estimating the prevalence of limb loss in the United States: 2005 to 2050. Arch Phys Med Rehabil. 2008;89(3):422-9.

4. Bloomquist T. Amputation and phantom limb pain: a pain-prevention model. AANA J. 2001:69(3):211-7.

5. Smith DG. General principles of amputation surgery. In: Rosemont IL, AAOS, editors. Atlas of amputations and limb deficiencies: surgical, prosthetic, and rehabilitation principles. 3th ed; 2004. p. 21-30.

6. Trevelyan EG, Turner WA, Robinson N. Perceptions of phantom limb pain in lower limb amputees and its effect on quality of life: a qualitative study. $\mathrm{Br}$. Pain. 2016;10(2):70-7.

7. Zidarov D, Swaine B, Gauthier-Gagnon C. Quality of life of persons with lower-limb amputation during rehabilitation and at 3-month follow-up. Arch Phys Med Rehabil. 2009;90(4):634-5.

8. International Association for the Study of Pain, Subcommittee on Taxonomy. Classification of chronic pain: descriptions of chronic pain syndromes and definitions of pain terms. Pain Suppl. 1986;3:S1-226.

9. Ehde DM, Smith DG. Chronic pain management. In: Smith DG, Michael JW, Bowker JH, Rosemont IL, AAOS, editors. Atlas of amputations and limb deficiencies: surgical, prosthetics, and rehabilitation principles. 3th ed; 2004. p. 711-26.

10. Kooijman CM, Dijkstra PU, Geertzen JH, Elzinga A, van der Schans CP. Phantom pain and phantom sensations in upper limb amputees: an epidemiological study. Pain. 2000;87(1):33-41.

11. Ephraim PL, Wegener ST, MacKenzie EJ, Dillingham TR, Pezzin LE. Phantom pain, residual limb pain, and back pain in amputees: results of a national survey. Arch Phys Med Rehabil. 2005;86(10):1910-9.

12. Dijkstra PU, Geertzen JH, Stewart R, van der Schans CP. Phantom pain and risk factors: a multivariate analysis. J Pain Symptom Manag. 2002; 24(6):578-85.

13. Nikolajsen L, Jensen TS. Phantom limb pain. Br J Anaesth. 2001;87(1):107-16.

14. Griffin SC, Tsao JWA. Mechanism-based classification of phantom limb pain. Pain. 2014;155(11):2236-42.

15. Giummarra MJ, Moseley GL. Phantom limb pain and bodily awareness: current concepts and future directions. Curr Opin Anaesthesiol. 2011:24(5):524-31.

16. Sherman RA, Sherman CJ, Parker L. Chronic phantom and stump pain among American veterans: results of a survey. Pain. 1984;18(1):83-95.

17. Bosmans JC, Geertzen JH, Post WJ, van der Schans CP, Dijkstra PU. Factors associated with phantom limb pain: a 31/2-year prospective study. Clin Rehabil. 2010;24(5):444-53.

18. Lyon CC, Kulkarni J, Zimerson E, Van Ross E, Beck MH. Skin disorders in amputees. J Am Acad Dermatol. 2000;42(3):501-7.

19. Koc E, Tunca M, Akar A, Erbil AH, Demiralp B, Arca E. Skin problems in amputees: a descriptive study. Int J Dermatol. 2008;47(5):463-6.

20. Meulenbelt HE, Geertzen JH, Jonkman MF, Dijkstra PU. Skin problems of the stump in lower limb amputees: 1. A clinical study. Acta Derm Venereol. 2011:91(2):173-7.

21. Yang NB, Garza LA, Foote CE, Kang S, Meyerle JH. High prevalence of stump dermatoses 38 years or more after amputation. Arch Dermatol. 2012;148(11):1283-6. 
22. Pet MA, Ko JH, Friedly JL, Mourad PD, Smith DG. Does targeted nerve implantation reduce neuroma pain in amputees? Clin Orthop Relat Res. 2014;472(10):2991-3001.

23. Souza JM, Cheesborough JE, Ko JH, Cho MS, Kuiken TA, Dumanian GA Targeted muscle reinnervation: a novel approach to postamputation neuroma pain. Clin Orthop Relat Res. 2014;472(10):2984-90.

24. Roux FE, Ibarrola D, Lazorthes Y, Berry I. Chronic motor cortex stimulation for phantom limb pain: a functional magnetic resonance imaging study: technical case report. Neurosurgery. 2001;48(3):681-8.

25. Bowen JB, Wee CE, Kalik J, Valerio IL. Targeted muscle reinnervation to improve pain, prosthetic tolerance, and bioprosthetic outcomes in the amputee. Adv Wound Care. 2017;6(8):261-7.

26. Sherman RA, Sherman CJ, Gall NGA. Survey of current phantom limb pain treatment in the United States. Pain. 1980;8(1):85-99.

27. Prantl L, Schreml S, Heine N, Eisenmann-Klein M, Angele P. Surgical treatment of chronic phantom limb sensation and limb pain after lower limb amputation. Plast Reconstr Surg. 2006;118(7):1562-72.

28. Kern KU, Kohl M, Seifert U, Schlereth T. Effect of botulinum toxin type B on residual limb sweating and pain. Is there a chance for indirect phantom pain reduction by improved prosthesis use? Schmerz. 2012;26(2):176-84.

29. Buvanendran A, Kroin JS, Rajagopal A, Robison SJ, Moric M, Tuman KJ. Oral ketamine for acute pain management after amputation surgery. Pain Med. 2017; https://doi.org/10.1093/pm/pnx229. [Epub ahead of print]

30. Wu Y, Keagy RD, Krick HJ, Stratigos JS, Betts HB. An innovative removable rigid dressing technique for below-the-knee amputation. J Bone Joint Surg Am. 1979;61(5):724-9.

31. What is assistive technology? how is it funded? http://www.atia.org/i4a/ pages/index.cfm?pageid=3859.

32. Padovani M, Martins M, Venâncio A, Forni J. Anxiety, depression and quality of life in individuals with phantom limb pain. Acta Ortop Bras. 2015;23(2):107-10.

33. Soin A, Shah NS, Fang ZP. High-frequency electrical nerve block for postamputation pain: a pilot study. Neuromodulation. 2015;18(3):197-205.

34. Rauck RL, Cohen SP, Gilmore CA, North JM, Kapural L, Zang RH, et al. Treatment of post-amputation pain with peripheral nerve stimulation. Neuromodulation. 2014;17(2):188-97.

35. Giuffrida O, Simpson L, Halligan PW. Contralateral stimulation, using TENS, of phantom limb pain: two confirmatory cases. Pain Med. 2010;11(1):133-41.

36. Mulvey MR, Bagnall AM, Johnson MI, Marchant PR. Transcutaneous electrical nerve stimulation (TENS) for phantom pain and stump pain following amputation in adults. Cochrane Database Syst Rev. 2015;8:CD007264.

37. SynchroMed II Infusion Pump. http://www.medtronic.com/content/dam/ medtronic-com-m/mdt/neuro/documents/pump-syc28637-ptmanl.pdf

38. Ferrante FM. Neuraxial infusion in the management of cancer pain. Oncology. 1999;13(5 Suppl 2):30-6.

39. Bosanquet DC, Glasbey JC, Stimpson A, Williams IM, Twine CP. Systematic review and meta-analysis of the efficacy of perineural local anaesthetic catheters after major lower limb amputation. Eur J Vasc Endovasc Surg. 2015;50(2):241-9.

40. Conine TA, Hershler C, Alexander SA, Crisp R. The efficacy of Farabloc in the treatment of phantom limb pain. Can. J Rehabil. 1993;6(3):155-61.

41. Hsiao AF, York R, Hsiao I, Hansen E, Hays RD, Ives J, et al. A randomized controlled study to evaluate the efficacy of noninvasive limb cover for chronic phantom limb pain among veteran amputees. Arch Phys Med Rehabil. 2012;93(4):617-22.

42. Zhang J, Clement D, Taunton J. The efficacy of Farabloc, an electromagnetic shield, in attenuating delayed-onset muscle soreness. Clin J Sport Med. 2000;10(1):15-21.

43. Kern U, Altkemper B, Kohl M. Management of phantom pain with a textile, electromagnetically-acting stump liner: a randomized, double-blind, crossover study. J Pain Symptom Manag. 2006;32(4):352-60.

44. Jacobs MB, Niemtzow RC. Treatment of phantom limb pain with laser and needle auricular acupuncture: a case report. Med Acupunct. 2011;23(1):57-60.

45. Dietrich C, Walter-Walsh K, Preissler S, Hofmann GO, Witte OW, Miltner WH, et al. Sensory feedback prosthesis reduces phantom limb pain: proof of a principle. Neurosci Lett. 2012;507(2):97-100.

46. Cole J, Crowle S, Austwick G, Slater DH. Exploratory findings with virtual reality for phantom limb pain; from stump motion to agency and analgesia. Disabil Rehabil. 2009;31(10):846-54

47. Arango JE, Mazo JC, PeñaPalacio A. Rehabilitation system for phantom limb syndrome using brain-computer interface and augmented reality. Iberian J Inform Technol. 2013;11:93-106.
48. Franz EA, Fu Y, Moore M, Winter T, Mayne T, Debnath R, et al. Fooling the brain by mirroring the hand: brain correlates of the perceptual capture of limb ownership. Restor Neurol Neurosci. 2016;34(5):721-32.

49. Leskowitz E. Phantom limb pain: an energy/trauma model. Exp Dermatol. 2014;10(6):389-97.

50. Ramachandran VS, Rogers-Ramachandran D. Synaesthesia in phantom limbs induced with mirrors. Proc Biol Sci. 1996;263(1369):377-86.

51. Ramachandran VS, Altschuler EL. The use of visual feedback, in particular mirror visual feedback, in restoring brain function. Brain. 2009;132(Pt 7): $1693-710$.

52. Imaizumi S, Asai T, Koyama S. Agency over phantom limb enhanced by short-term mirror therapy. Front Hum Neurosci. 2017;11:483.

53. Bogie KM, Garverick SL, Zorman CA, Daniel S, Howe DS. Integrated surface stimulation device for pain management and wound therapy. USA: The United States Government, as represented by the Department of Veterans Affairs; 2013.

54. Mackey DC, Mackey J. Method and device for acute pain management by simultaneous spinal cord electrical stimulation and drug infusion. In: Unlted States Patent. Edited by Patent US, A61N 1/04 edn. USA: Concessão; 1995.

55. Strother RB, Sakai JL, Joseph WB, Stager KW, Bennett ME, Rubin S. Systems and methods for providing percutaneous electrical stimulation. In: Vol. US8700177 B2. USA: Ndi Medical LIc; 2014.

56. Saab CY. Peripheral pain management. In: Vol. US8977362 B2. USA: Rhode Island Hospital; 2015.

57. Fang Z, Snyder JJ, Shah NS. High-frequency electrical nerve block. USA: Neuros Medical Inc.; 2015.

58. Halbert J, Crotty M, Cameron ID. Evidence for the optimal management of acute and chronic phantom pain: a systematic review. Clin J Pain. 2002; 18(2):84-92.

\section{Submit your next manuscript to BioMed Central and we will help you at every step:}

- We accept pre-submission inquiries

- Our selector tool helps you to find the most relevant journal

- We provide round the clock customer support

- Convenient online submission

- Thorough peer review

- Inclusion in PubMed and all major indexing services

- Maximum visibility for your research

Submit your manuscript at www.biomedcentral.com/submit
) Biomed Central 